\title{
2 \\ Ageing and social change in Australia
}

\section{Cathy Gong and Hal Kendig}

This chapter aims to provide a constructive understanding of social change and ageing in Australia. It presents a history of ideas and evidence on ageing in order to reveal the societal context that has shaped successive cohorts reaching later life. Contemporary commentators are reviewed to show evolving ways in which ageing has been conceptualised and 'problematised', thus shaping as well as reflecting expectations and interests concerning ageing and older people. The history provides a backdrop to the policy and social context for issues considered in later chapters and influences the scope for constructive change.

Central to this chapter and indeed to Australia's future, is the experience of the large post-war baby boom cohort that has been centre stage throughout the post-war era and is now entering later life. Baby boomers, along with overseas migrants, have led the 'younging' of Australia in earlier decades and now the 'ageing' of the population; both groups bring to later life varied life experiences that are fundamentally different from those of the Depression cohort now in advanced later life. The longevity revolution over recent decades, in which people are living many years beyond their 60s, is further reshaping the course of later life. Population ageing may be entering a new era in which lifelong economic prospects could be more limited 
for ascendant cohorts. Divergence of 'life chances' within cohorts, notably in terms of gender and socioeconomic resources, draws attention to social processes generating inequalities over the life-span and the implications for intergenerational relations, social justice and policy actions (Dannefer 2003).

This chapter begins with a brief history of ageing in Australia from colonial days to the present. It then considers the increasing longevity, capacities, and resources of ageing people while living longer. The discussion turns next to the remarkable changes in stages in lifespan experiences over the past few decades and recent shifts in people's expectations as to how they will fund their retirement. Outcomes for individuals and cohorts are considered in terms of economic resources and quality of life for age groups and generations. In the conclusion, critical issues of intergenerational equity are considered in the light of recent evidence on attitudes towards ageing and the socioeconomic prospects for cohorts into the future.

\section{Changing views on ageing}

Australia has long thought of itself as a 'young' country as we are reminded by the phrase 'for we are young and free' whenever the national anthem is sung. We have been slow in coming to think of ourselves as an ageing country and this has arguably restricted our capacities to respond constructively to ageing individuals and an ageing society. Although debatable, the significance of ageing for Australia, as a major social change, was largely invisible until the 1980s. Nevertheless, it is important to appreciate that the seeds of many negative responses to ageing, particularly in times of economic stress, have been sown and perpetuated for more than 100 years.

A penetrating analysis of Australia's early experiences in ageing was provided in Davison's (1995) 'Our Youth is Spent and our Backs are Bent: The Origins of Australian Ageism'. The conflation of the young age of the new colonies and the youthful European migrant population had some truth at the time (notwithstanding the now painful recognition that no account was taken of Aboriginal people and their ancient culture). In the 1850s, only 1 per cent of the population was aged 65 years or older, as a result of limited life expectancy and the youth of migrants who had left their older relatives in the 
'old country'. Concern for intergenerational conflict through the 1880s centred on newly affluent parents (notably in Victoria during the gold rush era) who were said to have invested heavily in children but who did not receive reciprocal support in turn as the parents reached old age.

Davison cites evidence that by the turn of the 20th century 'old age' was considered to begin at 55 years for women and 60 for men. The life-span at that time typically involved men entering the workforce at age 14 and remaining in work as long as health and opportunity allowed-often only into the 40s for manual workers. Compared to today, women had children early and continued through middle age; seldom was there an 'empty nest' before one or both parents had died. The Depression of the 1890s saw the numbers of the poorold increasing with homeless older people turning to charities and private asylums (and even prisons). At the time of Federation, state governments began to provide modest old age pensions to 'deserving persons of good moral character' ( $p$ 48), with the state thus defining retirement and old age.

The roots of Australian ageism arguably were located in the powerlessness of older people who were termed at the time as having a 'lack of vital energy in old age' (attributed in part to moral failure and poor health habits in middle age). Contemporary literature by middle-aged writers largely echoed these negative views, with disparaging depictions of 'old women'. Some early feminist writers, however, noted that preparation in mid-life could slow the 'inevitable' effects of ageing, and a release from domestic duty could potentially allow 'emancipation' for older women (p 55). 'Granny' remaining as a working member of the household was 'part of the natural order of things' ( $p$ 56). Davison concludes: 'The value of an historical approach is that it provides us with benchmarks against which we may measure current attitudes, and poses models of past change that might sensitise us to the forces transforming attitudes and structures to the present' (p 59).

A more recent account by Jalland (2015) covers the history of old age in Australia from 1880 to 1980, including policy-focused issues. She demonstrates the ongoing nature of many historical issues in ageing policies - including questions of user pays, means testing, and the balance of older peoples' autonomy, perceived worthiness, and the 
inevitable matter of constrained state resources and difficult choices for governments. Topic coverage includes state and federal government and department perspectives, retirement villages and aged care, and the failure of geriatric medicine from 1954-72. Drawing on family case studies, she establishes a sharp contrast between the lives of most older women and older men; and recounts improvements over the past 100 years, while cautioning that 'parsimonious' approaches continued into the post war era. As with Davison, she argues for the contemporary value of historical understandings of the early precedents of ageing policy; and raises concerns about the prospective inadequacy of government responses in the decades ahead.

After the watershed World War II years, Australia as with other countries was preoccupied by nation building and investment in economic and social development particularly for younger people. An early post-war advocate on ageing, Hutchinson (1954) argued that older people were being abandoned and isolated by 'modernisation' and that urgent housing and welfare measures were required on their behalf. The post-war era saw massive social change attributable to migration, increasing longevity, marriage and baby booms, increasing marital dissolution, rising home ownership and, perhaps most notable of all for economic wellbeing, the rising workforce participation among women and rising housing costs. Overall, the generations have remained close in emotional and mutual aid terms while they were increasingly living in separate households, by choice, as incomes rose and housing shortages eased (Kendig and Lucas 2014). The more recent rise of households with no workers and single parents, however, is accelerating income inequalities as housing markets and standards of living are increasingly set by two-income households.

Over the post-war era, older people have been increasingly recognised as a major disadvantaged group (National Commission of Inquiry into Poverty 1975) and included in universal health and welfare initiatives since the Whitlam Government. Recognition of population ageing as a major social change, however, was belated as is noted in McDonald's chapter. The National Population Inquiry (1975) made scant mention of ageing as one of the major social changes underway at the time. Not until a decade later did the National Population Council commission Greying Australia: Future Impacts of Population Ageing (Kendig and McCallum 1986), which anticipated future changes such as rising needs for care services, and increases in retirees relative to workers. 
Families, home ownership and rising education were identified as important resources for ascendant cohorts of older people. The report did not anticipate very well subsequent increases in longevity, and the rapid development of occupational superannuation and community care. Thirty years ago this report concluded that 'the view of old age as a defeated stage of life, so rampant today, is unlikely to last long when the baby boom joins the ranks of the aged' ( $p$ 59).

Over subsequent decades a series of academic books, including those with a social science and policy focus noted below, have charted changes in thinking about ageing along with evolving social and policy developments in the field:

- Howe's pioneering Towards an Older Australia (1981) set an early foundation for the study of ageing and gerontology. Its chapters describe and raise issues concerning older populations, their needs, and services (written by the few researchers who were working in the field at the time).

- Grey Policy: Australian Policies for an Ageing Society (Kendig and McCallum 1990) brought together growing national expertise in interpreting the ageing policy reforms by the Hawke/Keating Government of the 1980s.

- Ageing and Public Policy in Australia (Sax 1993), ' which began with the chapter 'Perceptions and Attitudes' and concluded with 'A Good Old Age', provided a comprehensive account of health and aged-care developments in a societal context.

- Ageing and Social Policy in Australia (Borowski et al. 1997), building on further research investments such as the Commonwealthfunded UNSW Social Policy Research Centre, provided more comprehensive accounts of what was to become the current policy framework of aged and health care, income support, superannuation and related policies.

\footnotetext{
1 This was the first of three books that Sidney Sax wrote after his 'retirement' from a distinguished career, which included practising in geriatric medicine, being head of the Commonwealth Social Welfare Policy Secetariat, and principal advisor on health and welfare to Prime Minister Malcolm Fraser. Sax served as the first President of the Australian Association of Geronontology.
} 
- Gibson's Aged Care: Old policies, new problems (1998) brought critical feminist and political economy perspectives to understanding ageing and dependency and key policy developments. For example, the book provides insights into complex topics such as 'Regulating Quality of Care' and 'The Problem of Older Women Redefined'.

- Contemporary Issues in Gerontology: Promoting positive ageing (Minichiello and Coulsen 2005), argues for a 'new gerontology' challenging the disease and decline approach to ageing, and included chapters on ageism, mental health, sexuality, and 'vehicles to promote positive ageing'.

- Longevity and Social Change in Australia (Borowski et al. 2007) reviewed developments primarily during the Howard/Costello era, widening the scope of ageing studies with chapters on lifelong learning, law, politics, advocacy, state governments, and the 'ageing without longevity' experienced by Indigenous Australians (Cotter et al. 2007).

Most recently, Challenges and Opportunities for an Ageing Australia (O'Loughlin et al. 2016) brings together CEPAR and health sciences researchers to present a constructive approach to population and policy issues in ageing (see also publications on www.cepar.edu. $\mathrm{au}$ ). The book includes a chapter on Indigenous health and ageing (Clapham and Duncan 2016) that brings the perspectives of Indigenous researchers to a better understanding of the lifelong disadvantage of their diverse peoples as well as appropriate support and care in their own communities. Another chapter (Radermacher and Feldman 2016) examines the complexity of 'addressing difference' in service systems inclusive of culturally and linguistically diverse communities.

Overall, these books show growing emphases on the positive contributions by older people, their wellbeing, and more effective and equitable policy responses, for example, in superannuation and health services. As indicated by the government's Intergenerational Reports, debates on population ageing are increasingly focused on rising costs to government, fiscal sustainability, and questions of intergenerational equity for younger people and their futures. Some themes are recurrent (and remain unresolved), for example, the vulnerability of groups experiencing lifelong disadvantages such as those of private tenants. There has been increasing attention to gender issues while important matters such as social class and politics (for the 
latter see Butler 2015) remain relatively less examined. The literature is enriched by increasing accounts from the viewpoints of older people and authors having experience across university research and education, public policy in government, and public advocacy.

\section{Increasing longevity}

The contours of later life in Australia have been changing, with life expectancy rising steadily since well before Federation (Figure 1). The usual life span has risen from the 50s age range in the 1890s to the 80 s age range in recent years. During the lifetimes of people alive today, social and economic life has had to adapt to the increasing proportions of older people in families and communities. The social meanings and consequences of death and the patterns of intergenerational relationships have changed dramatically as dying moved increasingly from babies and young mothers to men and women in advanced later life. Overall, the expectation for living into advanced older ages has become a 'normal' and relatively predictable part of contemporary life rather than the preserve of a small number of privileged survivors among past generations.

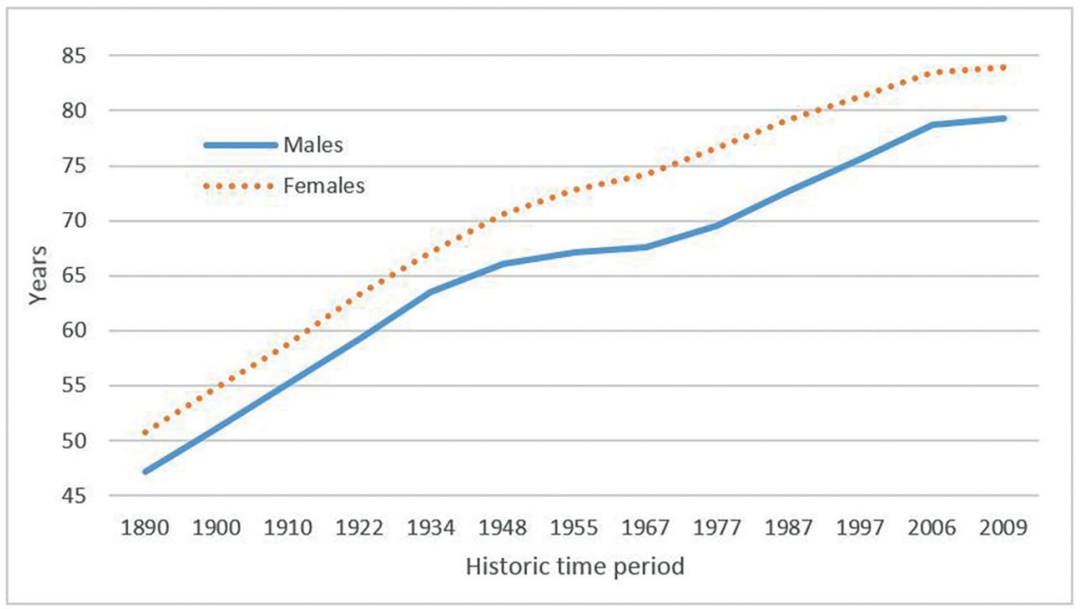

Figure 1. Life expectancy at birth in Australia by gender, 1884-2009

Source: Australian Bureau of Statistics (2011). 
The increases of life expectancy have included more years after reaching what traditionally have been the markers for entering later life. The trend has been continuing: from 1998 to 2012, life expectancy at 65 years increased from 16.1 to 19.1 years for men and from 19.8 to 22.0 years for women (Figure 2). Moreover, the additional years of later life included relatively more years free of disability; years of disability were increasingly being concentrated in the final years of life.

\section{Expected life years with and without disabilities}

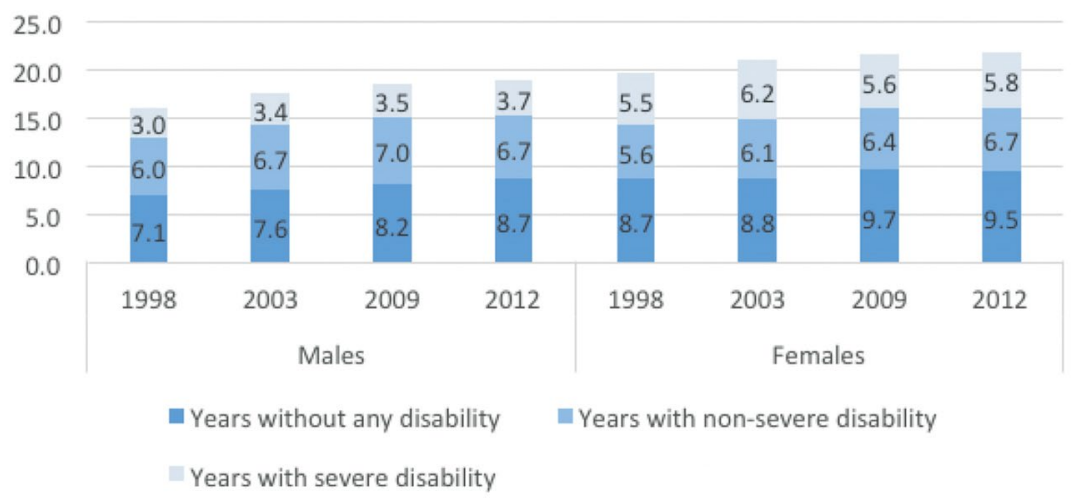

Figure 2. Expected life years with and without disabilities at age 65 in Australia, 1998-2012

Source: Australian Institute of Health and Welfare (2014).

Socioeconomic status is a key influence on inequalities of life expectancy. There is a life expectancy gap (at age 20) of six years between Australians in the top income quintile and those at the bottom income quintile; and a gap of five years between the highest and lowest quintiles for education (Clarke and Leigh 2011). An even greater socioeconomic disparity is seen in the 10-year life expectancy gap between Aboriginal and Torres Street Islanders and other Australians (AIHW 2011).

\section{Change in the life-span}

A life-span and social change framework provides a powerful way in which to understand age differences and ageing experiences over time. Lasslet's (1989) thinking on the 'new life course', enables us to 
consider the impacts of increasing longevity and social change on the 'second', 'third' and 'fourth' stages of life for successive cohorts and intergenerational relationships.

As shown in Figure 3, a life-span could be roughly defined in terms of four indicative ages according to capacities for productivity and independence: 1) a first age of dependency and education indicated by the average age of leaving parent's home (around age 21);2) a second age of independence and work to the average age of retirement (around age 59);3) a third age of independence and contribution until commencing care services (around age 80); and 4) a fourth age of significant dependency until death.

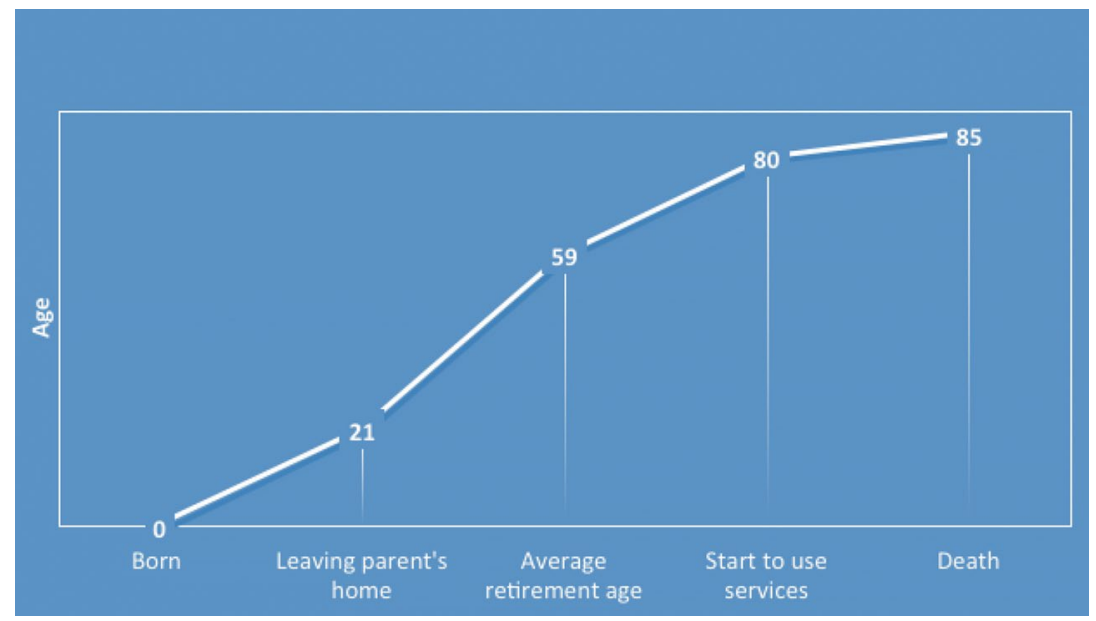

Figure 3. Indicative ages of four life stages across the life-span

Source: Gong's own work based on the data on social trends from Australian Bureau of Statistics (2012).

With increasing years of formal education and training, as required for a knowledge economy, and additional healthy years in late life, the first three stages have been lengthening, while the last stage continues to be concentrated in the final years of life. Since the 1970s, young people have tended to reach many of the major life milestones later, and this will have an impact on how many years they can work in total to support themselves.

In broad terms, there has been increasing scope for the emergence of the 'third age' - that is an extended period of relatively active life - prior to a 'fourth age' characterised typically by a few years in 
states of frailty and dependency. These trends have shifted Australian and global perspectives on ageing populations from an historical focus on 'welfare and health' to more emphases on the 'inclusion and participation' of older adults. This shift is reflected by more emphases over time in research and policy on 'active ageing' and 'healthy and productive ageing', focusing more on health promotion, employment and social engagement.

\section{Work and the 'second age'}

The 'second age' is the period of adult years characterised primarily by labour force participation and productivity. In the context of population ageing and possible workforce shortages, working longer can not only increase productivity and tax revenue, but also assist individuals to build up their own retirement income, thereby reducing the government's potential liability (Commonwealth of Australia 2015; McDonald 2011). With longer and relatively healthier life expectancies, working longer is becoming necessary and more feasible: a significant challenge is how to enable people to continue to work as mild chronic diseases or disabilities arise in their 50s and 60s (Richardson 2014).

Workforce participation has recently been increasing for women at working ages as well as for both men and women at mature age (Figure 4). Although participation in paid work for Australian women aged 55-64 has increased dramatically, much of this growth represents part-time rather than full-time work (ABS 2005). There are two factors contributing to these increases. One is that gender roles have changed significantly as more women have remained in the workforce through mid-life while also maintaining responsibilities as primary carers; by comparison men have been contributing only slightly more to family responsibilities (Richardson 2014). The other change is that more people have been planning later retirement. For instance, in 2007, the average age at which employed people intended to retire was 64 years for men and 62 for women. This was about five years later than the average age of 59 of reported retirement for those who were already retired at the time (60 years for men, 57 years for women) (ABS 2012). 


\section{Labour force participation rate by age and gender}

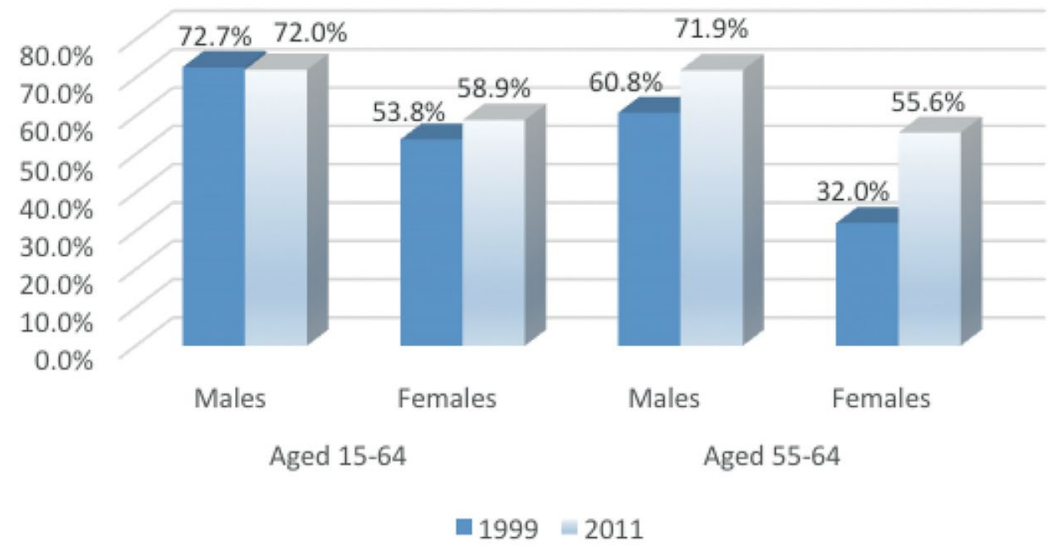

Figure 4. Labour force participation rate by age and gender in Australia, 1999-2011

Source: Australian Bureau of Statistics (2012).

\section{Ongoing contributions and the 'third age'}

The third age is the period after retirement, but prior to the onset of disability, in which individuals have the capacity to remain actively engaged (Laslett 1989). With recent increases in living standards and healthy life years after retirement, people in the third age have been able to expect to enjoy a life with self-fulfilling leisure and community participation after completing their responsibilities for paid work and dependent children (Chatzitheochari and Arber 2011). Realising these opportunities may require significant individual and societal adaptations by people at all ages in their family and social life as well as among employers and community organisations.

The emergence of a longer third age and the additional years of good health in later life provide a critical focus for considering social opportunities, risks and action possibilities for an ageing society (Biggs 2014). In Australia, older people already make substantial contributions beyond paid work to their families and the wider community through volunteering and other forms of unpaid work 
(Loh and Kendig 2013). For example, their child care and caregiving to family members was valued conservatively at $\$ 7$ billion in 2009 (National Seniors Australia 2009).

\section{A shift is underway in how people expect to fund their retirement}

The Australian retirement income system consists of three major components: the age pension, superannuation and other private savings. The age pension has developed as a social welfare safety net, providing a modest income for those who are not able to support themselves during retirement and a supplement for those with some private resources. Currently, government pensions and allowances are by far the most common source of personal retirement income for both men and women, with around two-thirds of both sexes relying on these as their main source of income.

With the introduction of the superannuation guarantee in 1992, coverage increased substantially and the gender gap has narrowed. In 1974, only 32 per cent of employees (41 per cent of men and 17 per cent of women) were covered by superannuation and they were generally higher paid professionals, managers and administrators in large corporations and the financial sector, as well as public servants and members of the defence force. By 1991, nearly one-third of private sector employees still had no superannuation (Warren 2008). In 1993, just after the introduction of the superannuation guarantee, 81 per cent of employed persons (86 per cent of full-time workers and 61 per cent of part-time workers, 82 per cent of employed men and 78 per cent of employed women) were covered by superannuation (Warren 2008).

The government age pension is still expected to be the main source of retirement income for the next two or three decades until the occupational superannuation system is fully mature (Warren 2008). In 2007, only 25 per cent of adult men and 10 per cent of adult women listed superannuation as their primary source of expected retirement income. The expectations of younger workers suggests that it will be decades before superannuation becomes the main source of retirement income as it is likely to rise moderately and slowly. This change reflects the impact of compulsory superannuation initiatives that were introduced in the late 1980s and early 1990s. 
There has been a lengthy debate that the age pension replacement rate (the pension compared to earlier earnings) in Australia is low among OECD countries, although it has been compensated to some extent by the low housing outlays afforded by a higher home ownership rate among older Australians (see Appendix 1 and Chapter 13). However, difficulties meeting the high entry costs of buying present major challenges for younger generations.

The gender gap in retirement incomes requires emphasis. First, women's labour force participation has been limited (notably due to childbearing and child rearing) and marked by more interruptions, more part-time work, and lower rates of pay, hence less superannuation and wealth accumulation. Second, women are likely to live significantly longer than men, including more years requiring what can be expensive aged care. Third, marital breakdown and widowhood present particularly severe financial risks for women.

\section{Outcomes for individuals and cohorts}

\section{Economic resources}

Historically, Australia has been regarded as a country of egalitarian values with relatively equal distribution of wealth, a lack of visible poverty and generally comfortable incomes. In the 1960s, Prime Minister Harold Holt stated that he knew of no other free country where 'what is produced by the community is more fairly and evenly distributed among the community' (Whiteford 2014). However, this view of Australia came under scrutiny from the 1980s onwards as inequality increased rapidly: from around 2010, Australia became the 11th 'most unequal' of the 34 OECD members. At that time, the richest 20 per cent had 61 per cent of the wealth, while the poorest 20 per cent accounted for a mere 1 per cent of total household net worth (Whiteford 2014).

Over recent decades, poverty in Australia has encompassed more vulnerable groups beyond older pensioners, including more single parents, unemployed youth and other groups, especially those who rent privately. The Productivity Commission reported that people aged 65 years and over (especially singles) nonetheless remain at high risk of experiencing deeper or multiple forms of disadvantage (McLachlan 
et al. 2013; see also Gong et al. 2014). Among elderly singles in 2010, the vast majority of whom were women, 24 per cent experienced relative income poverty. People aged 65 years and over are far more likely to experience persistent poverty than average households (6.3 per cent compared to 4.4 per cent) (Table 1 ).

Table 1. Prevalence of forms of disadvantage among older Australians, 2010 (\%)

\begin{tabular}{|l|c|c|c|c|}
\hline & $\begin{array}{c}\text { Relative income } \\
\text { poverty 2010 }\end{array}$ & $\begin{array}{c}\text { Multiple } \\
\text { deprivation } \\
2010\end{array}$ & $\begin{array}{c}\text { Deep social } \\
\text { exclusion } \\
2010\end{array}$ & $\begin{array}{c}\text { Deep and persistent } \\
\text { social exclusion } \\
\text { 2001 and 2010 }\end{array}$ \\
\hline $\begin{array}{l}\text { Single adults } \\
\text { over 65 years }\end{array}$ & 23.6 & 3.3 & 11.9 & 6.3 \\
\hline $\begin{array}{l}\text { Total adults } \\
\text { over 65 years }\end{array}$ & 13.2 & 7.9 & 7.6 & 6.3 \\
\hline Total & 12.8 & 13.2 & 4.8 & 4.4 \\
\hline
\end{tabular}

Source: McLachlan, Gilfillan and Gordon (2013), Table 1.

Notes: (1) Relative income poverty is defined as the household equivalised income being less than 50 per cent of the median household equivalised income.

(2) Multiple deprivation indicates a combination of low income, low consumption and low net wealth.

(3) Deep social exclusion was defined by 29 indicators across seven key life domains (including material resources, employment, education and skills, health and disability, social connection, community and personal safety).

(4) Deep and persistent social exclusion is defined as the household was having deep social exclusion in both years of 2001 and 2010.

A recent report on the wealth of generations by the GRATTAN Institute indicates that property and savings have driven wealth accumulation differently across age groups from 2003-04 to 2011-12 (Daley and Wood 2014). As a result of increases in housing prices, accumulated superannuation and other invested savings, the net wealth of people aged 45 and over increased substantially: people aged 65 to 74 have benefited most with an annual growth of net wealth of 2.9 per cent, followed by 2.6 per cent for people aged 75 and over. At the same time, households headed by those under 35 have had less wealth in their homes than did the same group eight years ago. They have to borrow more relative to income in order to adapt to the declining housing affordability, although compulsory superannuation could boost their lifetime savings to some extent. 


\section{Age and cohort changes}

Longitudinal research is beginning to shed light on how ageing and social change are related to inequalities over the life-span and the implications for social justice and policy actions. As indicated in Figure 5, successive birth cohorts have experienced different social, economic and policy circumstances during their childhood, education, work and retirement. For instance, the Depression generation born in the 1930s entered into late life in 1990 and the large baby boom cohort born in the 1950s is now gradually arriving in what has traditionally been regarded as later life.

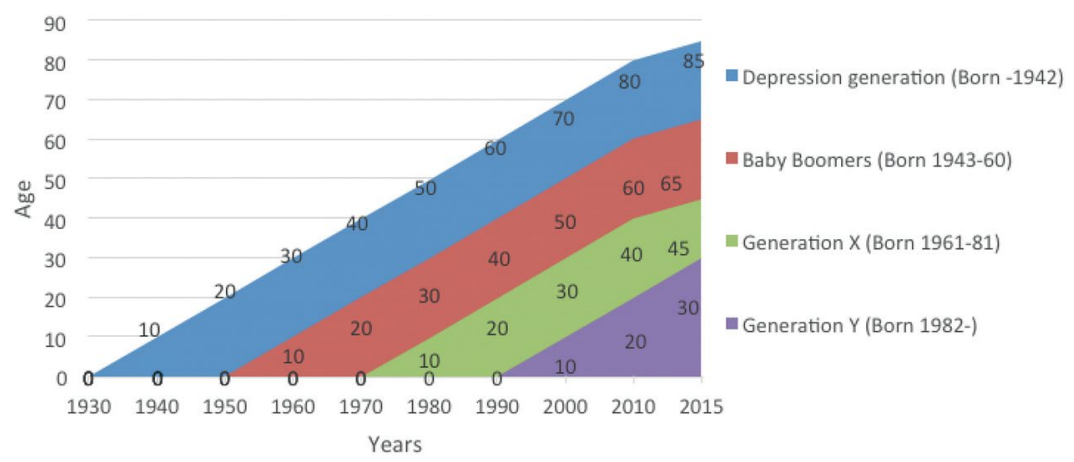

Figure 5. Indicative age, cohort and time period

Source: Gong's own work based on the definitions of generational cohorts.

Figure 6 presents the major global economic events that occurred from the 1930s to 2015, helping to provide historical context for the experiences of different generational cohorts. The post-World War II era has provided the fundamental historical context for understanding the changing face of ageing in Australia, and set legacies that are still influencing future directions. The shock of the 2007 global financial crisis (GFC), after 25 years of strong economic growth, changed perceptions of the adequacy of expected retirement incomes, although in contrast to the recession of the early 1990s it did not result in largescale unemployment for older workers. It also increased policy and public concern for the costs of population ageing, and led to increased access to partial age pensions and other changes in the direction of government policies (Kendig et al. 2013). 


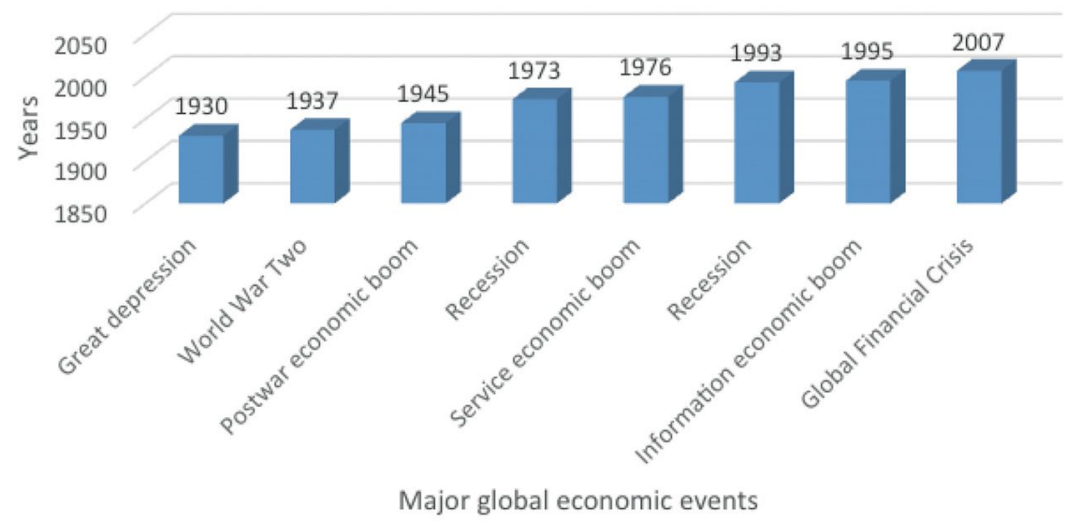

Figure 6. Indicative historic major global economic events, 1930-2015 Source: Gong's own work based on the well-known major historical events.

Four generational cohorts can be defined by their periods of birth and their subsequent exposures to global economic environments over recent decades (Figure 6). These generations can be characterised in terms of related social values, attitudes and behaviours:

- The Depression generation, the current cohort of older people who were born in 1944 or before, grew up in the Great Depression and World War II during the 1930s and 1940s with low education but access to full-time and relatively less-skilled employment when they were young (Carson and Kerr 2001). They subsequently experienced tremendous changes in work patterns, such as the rapid decline of the manufacturing sector, and restructuring that had particularly severe consequences for low-skilled workers, including precarious employment prospects and increasing risks of long-term unemployment in mid- and late life.

- Baby boomers, who were born between 1945 and 1960, grew up in the post-war economic boom era, characterised by rising educational and employment opportunities, with relatively less gender inequality on entering adulthood (Carson and Kerr 2001; Biggs 2014). Their expanding opportunities and resources contrast sharply with the limited expectations and economic opportunities of the Depression generation who have, thus far, shaped images of ageing. 
- The Younger generation (Generation X born 1961-1981 and Generation Y born 1982 or later), who grew up or entered adulthood during the slow and/or variable economic growth of the early 1970s, the early 1990s and then the GFC in the early 21 st century, with the expanding tertiary sector. They have faced a more uncertain economy with less job security and higher income inequality, with more demand for adaptability to changes (Tetrick and LaRocco 1987; McDaniel et al. 2013). We have included only Generation $\mathrm{X}$ in this study by restricting individuals to those aged 35 and over in the data analysed from the Household, Income and Labour Dynamics in Australia (HILDA) surveys of 2001 to 2011.

Cohort succession is significantly increasing diversity in later life and generating new perspectives on ageing. The GFC of 2007 and diminishing public programs over recent years have further changed perspectives. Younger generations will be particularly affected by rising income inequality and reduced expectations for job security, income growth, health care and other public benefits (for Canada see also McDaniel et al. 2013). Among the Australian generational cohorts, the baby boomers are commonly thought to be the most advantaged on the basis of their rising educational and employment opportunities and the booming residential housing market through the 1980s and 1990s.

\section{Recent changes in life satisfaction}

This section examines the ways in which ageing and social change are related to quality of life as indicated by life satisfaction through adult life from the turn of the century. The opportunity to examine these issues arose with the longitudinal HILDA study that has surveyed Australians annually since 2001 (Summerfield et al. 2012).

Figure 7 (top three lines) shows that over the first decade of this century (from 2001 to 2011), overall life satisfaction increased slightly for the ageing baby boomers while they were moving towards later life. For the older Depression cohort, life satisfaction was higher than for the boomers, notwithstanding their advanced age, and it remained largely steady as they moved through to advanced old age. For the young cohort, however, life satisfaction on average was relatively lower when compared to the two older generations and declined slightly as they moved towards middle age. 
In terms of satisfaction with health (bottom three lines), there was an understandable but only modest decline for all the three generations with increasing age. Overall, the findings suggest considerable stability of satisfaction with life and health as the birth cohorts have been moving through middle to later life. However, in interpreting these findings it is important to keep in mind that people who were very old and/or in poor health in 2001 were more likely to have died before 2011.

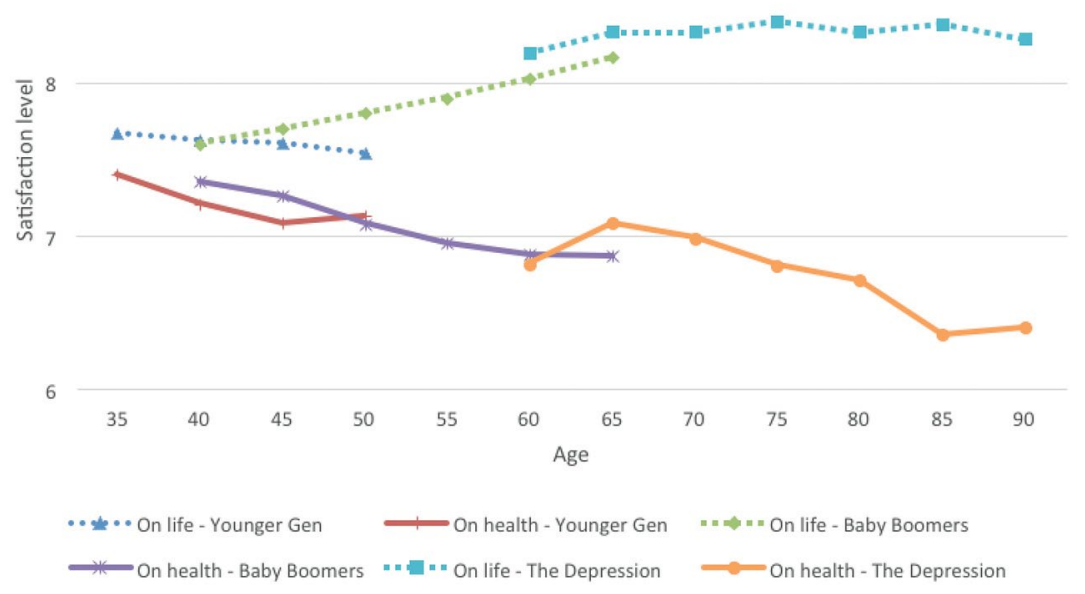

Figure 7. Satisfaction levels with life overall and health by age and cohort Source: HILDA 2001-2011, Gong's own calculation.

More detailed findings (not shown on the figure) show that overall education and health confer relatively higher levels of health and life satisfaction across the cohorts:

- The Depression birth cohort had a relatively higher level of satisfaction in specific areas of life - free time, home, neighbourhood, local community and relationships with partner, children and parents, with very little decline in these areas with ageing even for those at advanced ages.

- The youngest cohort had the highest satisfaction with financial situation and employment opportunities (but this declined slightly as mid-life approached). 
- The baby boomers cohort had the least satisfaction in relationships with their children, although this was rising over the 10 years.

- The younger generation cohort had achieved the highest education levels followed by the baby boomers and then by the Depression cohort.

- For all birth cohorts, higher education is associated with better selfreported health as well as higher satisfaction with life overall, financial situation, employment opportunity and living environment (but lower satisfaction with free time and relationships).

- Again for all cohorts, women have relatively slightly higher life satisfaction levels than men; life satisfaction is the highest for those reporting excellent health (and it decreases significantly for those in poor health).

- The better-educated in the young generation were slightly more satisfied with their life overall than their peers at other ages. Education beyond high school conferred relatively less advantage for baby boomers; and it conferred more advantage for those in the Depression cohort who had certificates or more education. The findings suggest that requirements for education and skill sets have increased over time for successive cohorts.

Other studies indicate significant overall impacts of the GFC on satisfaction with health and life. A national survey of baby boomers showed that the GFC was a significant 'shock' for their financial expectations, especially for those who were still employed compared to those who were retired at the time (Kendig et al. 2013). A longitudinal study in Canberra concluded that the GFC had a delayed effect in increasing depression and anxiety, particularly among baby boomers whose expectations for high standards of living in retirement apparently were threatened (Sargent-Cox et al. 2011).

\section{The future and intergenerational equity}

Anticipating directions for the future is important to inform and guide constructive action, notwithstanding the difficulty of unforeseen developments such as the GFC. It is heartening that there has been notable progress for older people over recent generations along with rising standards of living in Australia. Understanding the past is important for appreciating social progress and also the cultural and 
institutional inertia in social organisation, including the relative positions and power of various interests that can shape and resist change.

The expectation for a longer and healthier 'third age', with more scope for productivity in paid and unpaid work, is now being realised for the majority of ageing people. Their socioeconomic standing, notably with wealth in owner-occupied housing, has risen appreciably. Their psychological wellbeing overall is high relative to those in middle age and it appears to improve as people approach later life. There remain, however, pockets of intense deprivation among older people as there are among younger age groups. Notable disadvantage continues among older Aboriginals, women without partners, non-home owners, and those in poor health, including rises in the prevalence of chronic disease.

Some aspects of the future are relatively easy to anticipate. Baby boomers now in late-middle age have been advantaged by their educational and career opportunities from the 1960s and 1970s; they are now bringing these resources, life skills and expectations to their later life. Family relations are evolving in complex and varied ways but intergenerational bonds are deeply seated and generally remain strong. Housing assets for this cohort are generally high as a result of increased access to home ownership and appreciating real values from the 1980s onward. Superannuation accumulating since the 1990s, with substantial employer contributions and tax subsidies, will be maturing.

The cohort momentum behind these promising directions for older people is in some ways reversing earlier patterns in which people had been disadvantaged by their cohort of birth as well as ageing. The major proviso here, of course, is that the 'accumulation' of advantage has not been available to all groups of older (and younger) people and socioeconomic disparities appear to have been increasing. Current directions are for older single women to continue to be at a substantial disadvantage relative to men in terms of their vulnerability to poverty, poor health, and housing insecurity.

Attitudes to ageing and older people have also evolved since the 'ageism' in the colonial era of 'a society without grandmothers' (Davison 1995). A CEPAR-supported national Attitudes to Ageing in Australia 
(AAA) study (Kendig et al. 2015) in 2010 found that the majority of younger people at the time were sympathetic to policies beneficial to older people as most believed that they were getting 'less than their fair share of government benefits'. O'Loughlin and Kendig (2016), drawing on this same data base, report that attitudes on the capacities of older people, however, were less favourable: the findings indicate considerable ambivalence and negativity towards older people in the workplace. Across all age groups only a small proportion of people perceived strong intergenerational conflict. There were divided views on the lifelong opportunities of the baby boom cohort as compared to those who are following them.

There are uncertain prospects for directions in real incomes, wealth, and the future of work. An optimistic note is struck in the otherwise pessimistic Intergenerational Report (Commonwealth of Australia 2015), which, in its technical document, assumes growth of real income into the future. Home ownership, which has proved so important to mitigate the effects of reduced income in later life, is projected to decline for future cohorts of older and younger people (Stebbing and Spies-Butcher 2015). Employment is central to accumulating resources for one's own later life and also for taxation supporting public transfer programs. While workforce participation has been increasing at older ages, ageing workers are likely to be in industries and occupations where jobs are under major threat from technological change and reorganisation of workplaces (CEDA 2015). Economic modeling has shown that the recent direction of government budgets has been to widen inequalities between the rich and poor and between the younger and older generations (Phillips 2015).

Notwithstanding the significant concerns and uncertainties ahead, the chapters in this volume indicate that Australia is relatively well placed in terms of its demography, economy, and policies to respond constructively to population ageing. We may, however, be at a turning point in which future generations may well have lower lifelong economic prospects than the baby boom cohort now entering later life. Further, experiences over the life course are becoming more precarious for many in terms of family and work life. While some older people will continue to be disadvantaged by poor health and limited financial resources, the overall pattern is for older people to have an increasing 
share of national wealth. This growing trend for at least a decade ahead raises the capacities of advantaged older people to pay for services and to contribute more to their families and to government revenue.

The future can be influenced positively by governments, employers, and individuals that take action on the considerable potential for 'improvability' for an ageing Australia. Big ideas that can assist in achieving better wellbeing outcomes include building human capital over the entire life span; 'ageing well' approaches in health and social policy; and employment and care practises that reinforce independence (Kendig 2016). Positive outcomes for all age groups and generations can be facilitated by further social change that recognises diversity over the life span and fosters positive attitudes and opportunities for older people.

\section{References}

Australian Bureau of Statistics (ABS) (2005). Australia Labour Market Statistics, January 2005. ABS Cat. no. 6105.0. Canberra: Australian Bureau of Statistics.

Australian Bureau of Statistics (ABS) (2011). Australian Social Trends: Life Expectancy Trends, March 2011. ABS Cat. no. 4102.0. Canberra: Australian Bureau of Statistics.

Australian Bureau of Statistics (ABS) (2012). Australian Social Trends, December 2012. ABS Cat. no. 4102.0. Canberra: Australian Bureau of Statistics.

Australian Institute of Health and Welfare (AIHW) (2011). The health and welfare of Australia's Aboriginal and Torres Strait Islander people, an overview 2011. Cat. no. IHW 42. Canberra: AIHW.

Australian Institute of Health and Welfare (AIHW) (2014). Healthy Life Expectancy in Australia: Patterns and trends 1998 to 2012. Australian Institute of Health and Welfare. Bulletin no. 126. Cat. no. AUS187. Canberra: AIHW.

Biggs Simon (2014). Adapting to an ageing society: The need for cultural change. Policy Quarterly, 10(3): 12-16. 
Borowski Allan, Encel Sol and Ozanne Elizabeth (Eds) (1997). Ageing and Social Policy in Australia. Cambridge: Cambridge University Press.

Borowski Allan, Encel Sol and Ozanne Elizabeth (Eds) (2007). Longevity and Social Change in Australia. Sydney: University of New South Wales Press.

Butler Mark (2015). Advanced Australia: The Politics of Ageing. Melbourne: Melbourne University Press.

Carson Ed and Kerr Lorraine (2001). Bust for the 'baby-boomers': The real mid-life crisis. Journal of Economic and Social Policy, 6(1): art.5.

Chatzitheochari Stella and Arber Sara (2011). Identifying the Third Agers: An Analysis of British Retirees' Leisure Pursuits. University of Surrey. Sociological Research Online, 16(4): 3.

Clapham Kathleen and Duncan Cathy (2016). Indigenous Australians and Ageing: Responding to Diversity in Policy and Practice. In Kate O'Loughlin, Colette Browning and Hal Kendig (Eds). Ageing in Australia: Challenges and Opportunities. New York: Springer.

Clarke Phillip and Leigh Andrew (2011). Death, Dollars, and Degrees: Socioeconomic Status and Longevity in Australia. Economic Papers, 30(3): 348-355.

Committee for Economic Development of Australia (CEDA) (2015). Australia's future workforce? Committee for Economic Development of Australia, June 2015. dx.doi.org/10.4225/50/557FA860CD297.

Commonwealth of Australia (2015). 2015 Intergenerational Report: Australia in 2055. Canberra: Department of Treasury, March 2015. www.treasury.gov.au/PublicationsAndMedia/ Publications/2015/2015-Intergenerational-Report.

Cotter Philippa, Anderson Ian and Smith Len (2007). Indigenous Australians: Ageing Without Longevity. In Allan Borowski, Sol Encel and Elizabeth Ozanne (Eds) Longevity and Social Change in Australia. Sydney: University of New South Wales Press, pp. 65-98.

Daley John and Wood Danielle (2014). The Wealth of Generations. Melbourne: GRATTAN Institute. grattan.edu.au/report/the-wealthof-generations/. 
Dannefer Dale (2003). Cumulative advantage/disadvantage and the life course: Cross-fertilizing age and social science theory. Journals of Gerontology Series B: Psychological Sciences and Social Sciences, 58(6): S327-337.

Davison Graeme (1995). Our Youth is Spent and our Backs are Bent: The Origins of Australian Ageism. Australian Cultural History, 14: $40-62$.

Gibson Diane (1998). Aged Care: Old policies, new problems. Cambridge: Cambridge University Press.

Gong Cathy, Kendig Hal, Harding Ann, Miranti Royara and McNamara Justine (2014). Economic Advantage and Disadvantage among Older Australians: Producing National and Small Area Profiles. Australasian Journal of Regional Studies, 20(3): 513-539.

Howe Anna L (Ed) (1981). Towards an Older Australia. St Lucia, Queensland: University of Queensland Press.

Hutchinson Bertram (1954). Older People in a Modern Australian Community: A Social Science Survey. Melbourne: Melbourne University Press.

Jalland Patricia (2015). Old age in Australia: A History. Carlton, Victoria: Melbourne University Press.

Kendig Hal (2016). Directions and Choices for the Future. In Kate O'Loughlin, Colette Browning and Hal Kendig (Eds), Ageing in Australia: Challenges and Opportunities. New York: Springer.

Kendig Hal and Lucas Nina (2014). Individuals, Families and the State: Changing responsibilities in an aging Australia. In Amaryllis T Torres and Laura L Samson (Eds), Aging in Asia-Pacific: Balancing the State and the Family. Diliman, Philippines: Philippine Social Science Council.

Kendig Hal and McCallum John (1986). Greying Australia: Future Impacts of Population Ageing. Canberra: Australian Government Publishing Service.

Kendig Hal and McCallum John (1990). Grey Policy: Australian Policies for an Ageing Society. Sydney: Allen \& Unwin. 
Kendig Hal, O'Loughlin Kate, Hussain Rafat, Heese Karla and Cannon Lisa (2015). Attitudes to Intergenerational Equity: Baseline Findings from the Attitudes to Ageing in Australia (AAA) Study. CEPAR Working Paper, 2015/33. Sydney: ARC Centre of Excellence in Population Ageing Research.

Kendig Hal, Wells Yvonne, O'Loughlin Kate and Heese Karla (2013). Australian baby boomers face retirement during the Global Financial Crisis. Journal of Aging and Social Policy, 25(3): 264-280.

Laslett Peter (1989). A Fresh Map of Life: The emergence of a third age. London: Weidenfeld and Nicolson.

Loh Vanessa and Kendig Hal (2013). Productive engagement across the life course: Paid work and beyond. Australian Journal of Social Issues, 48(1): 111-137.

McDaniel Susan A, Gazso Amber and Um Seonggee (2013). Generationing relations in challenging times: Americans and Canadians in mid-life in the Great Recession. Current Sociology, 61(7): 931-948.

McDonald Peter (2011). Employment at Older Ages in Australia: Determinants and Trends. In Tabatha Griffin and Francesca Beddie (Eds) Older Workers: Research Readings. Adelaide: NCVER.

McLachlan Rosalie, Gilfillan Geoff and Gordon Jenny (2013). Deep and Persistent Disadvantage in Australia, Canberra: Productivity Commission, Staff Working Paper.

Minichiello Victor and Coulsen Irene (2005). Contemporary Issues in Gerontology: Promoting positive ageing. Sydney: Allen \& Unwin.

National Commission of Inquiry into Poverty (1975). Poverty in Australia. Canberra: Australian Government Publishing Service.

National Population Inquiry (1975). Population and Australia: A demographic Analysis and Projection, 2 volumes. Canberra: Australian Government Publishing Service.

National Seniors Australia (2009). Still Putting In: Measuring the Economic and Social Contributions of Older Australians, Research Report, National Seniors Australia Productive Ageing Centre. Canberra: Department of Health and Ageing. 
O'Loughlin Kate and Kendig Hal (2016). Attitudes to Ageing. In Kate O'Loughlin, Colette Browning and Hal Kendig (Eds), Ageing in Australia: Challenges and Opportunities. New York: Springer.

O'Loughlin Kate, Colette Browning and Hal Kendig (Eds), Ageing in Australia: Challenges and Opportunities. New York: Springer.

Phillips Ben (2015). Living Standard Trends in Australia: Report for Anglicare Australia. NATSEM, University of Canberra, September 2015. www.natsem.canberra.edu.au/storage/Living \%20Standard $\% 20$ Trends\%20Final.pdf.

Radermacher Harriet and Feldman Susan (2016). Cultural Diversity, Health and Ageing. In Kate O'Loughlin, Colette Browning and Hal Kendig (Eds), Ageing in Australia: Challenges and Opportunities. New York: Springer.

Richardson Susan (2014). Do We All Want Permanent Full-time Jobs? Insights, 15(April).

Sargent-Cox Kerry, Butterworth Peter and Anstey Kaarin (2011). The global financial crisis and psychological health in a sample of Australian older adults: A longitudinal study. Social Science and Medicine, 73(7): 1105-1112.

Sax Sidney (1993) Ageing and Public Policy in Australia. Sydney: Allen \& Unwin.

Stebbing Adam and Spies-Butcher Ben (2015). The decline of a homeowning society? Asset-based welfare, retirement and intergenerational equity in Australia. Housing Studies 31(2). doi: 10.1080/02673037.2015.1070797.

Summerfield Michelle, Freidin Simon, Hahn Markus, Ittak Peter, Li Ning, Macalalad Ninette, Watson Nicole, Wilkins Roger and Wooden Mark (2012). HILDA User Manual — Release 11, Melbourne Institute of Applied Economic and Social Research, University of Melbourne.

Tetrick Lois E and LaRocco James (1987). Understanding, prediction and control as moderators of the relationships between perceived stress, satisfaction, and psychological well-being. Journal of Applied Psychology, 72(4): 538-543. 
Warren Diana (2008). Australia's Retirement Income System: Historical Development and Effects of Recent Reforms. Melbourne Institute Working Paper Series, Working Paper No. 23/08.

Whiteford Peter (2014). Income and wealth inequality: How is Australia faring? The Conversation. 5 March 2014. 
This text is taken from Population Ageing and Australia's Future, edited by Hal Kendig, Peter McDonald and John Piggott, published 2016 by ANU Press, The Australian National University, Canberra, Australia. 